\title{
EL PAPEL DE LOS JUEGOS EN LA TRANSMISIÓN CULTURAL: LOS POEMAS HOMÉRICOS Y LAS OLIMPIADAS EN LA SOCIEDAD ORAL GRIEGA
}

Luis Cantarero

UNIVERSIDAD DE ZARAGOZA

\begin{abstract}
RESUMEN
La intención de este trabajo es revelar el papel de los juegos en la cultura oral griega. A modo de introducción resumimos los rasgos más generales y característicos del oralismo. Una vez situados en el contexto general veremos que los juegos descritos en los poemas homéricos y los que se realizaban en la Grecia clásica -Olímpicos, Píticos, Ístmicos y Nemeos- tenían dos funciones primordiales: proporcionar entretenimiento y construir un orden social; orden que, como mostramos en las siguientes líneas, viene sintetizado por los valores que aglutina el héroe homérico y olímpico: el noble-deportista-amateur.
\end{abstract}

\section{INTRODUCCIÓN}

Cuando se comienza a estudiar filosofía antigua algo que sorprende es la noticia de la ausencia de escritura en una sociedad como la griega ${ }^{1}$ que ha sido considerada por muchos como el prototipo de la civilización occidental. Para una mentalidad contemporánea resulta casi imposible hacerse una idea de cómo sería una colectividad, como la del siglo VIII a. C. (y anterior), sin soporte escrito; una sociedad de la oralidad primaria que se apoyaba exclusivamente en la palabra hablada para transmitir sus doctrinas y asegurarse su funcionamiento. Un discurso oral que era necesario retener para perpetuar la existencia

\footnotetext{
${ }^{1}$ Hasta el siglo VIII a. C. la sociedad griega era la de la oralidad primaria. Desde entonces y hasta Aristóteles (siglo IV a. C.), los griegos compartieron oralidad y escritura. Esta transición la explica de una manera muy acertada (Havelock, 1996) La musa aprende a escribir. Reflexiones sobre oralidad y escritura desde la Antigüedad hasta el presente. Barcelona. Paidós. Las tragedias y las comedias muestran rasgos de la cultura alfabetizada. El Hipólito de Eurípides lo ejemplifica. La escena que permite esta aseveración es bien conocida: Fedra se ahorca e incrimina, por escrito, a su hijastro (Hipólito). Teseo lee el mensaje que Fedra ha escrito en una tablilla y que ha suspendido de su mano. En esta escena se ampara Havelock para afirmar que la musa de la oralidad (cantora, recitadora, memorizadora) está aprendiendo a leer y escribir (Havelock, 1996: 45).
} 
social. Escuchar y memorizar eran, por tanto, dos virtudes intelectuales en la época de Homero, Hesíodo y de los primeros filósofos presocráticos.

Pues bien, los estudiosos han concluido que lo que garantizaba la memorización del discurso oral — que se transmitía a las generaciones posteriores - era el habla rítmica; un habla repetitiva que se presentaba en ocasiones asociada con la danza, la música y los banquetes. Es decir, se acompañaba de acontecimientos lúdicos que recreaban un contexto favorable a la escucha y a la retentiva. Era también un habla cuyos contenidos eran acciones. Gracias a estas dos características (ritmo y relato de acción), el habla rítmica facilitaba la permanencia de los recuerdos, la asimilación de normas culturales, la adquisición de creencias sociales y el aprendizaje de los saberes prácticos.

La poesía aglutinaba ambas características: es verso con función mnemónica y texto narrativo repleto de personajes que actúan. Por lo tanto, en las sociedades de la oralidad, amén de su empleo lúdico, la poesía tenía una función didáctica incuestionable: transmitía la tradición, la lógica cívica y social. Rapsodas, sacerdotes, músicos, cantores etcétera, la usaban para transmitir la cultura que retienen en su memoria. Así resolvieron los griegos la ausencia de escritura.

Poco a poco, ante la necesidad de fijar los acontecimientos que van desde el siglo XV a. C., en adelante, surgen los primeros textos escritos en verso: Ilíada y Odisea. Ambos poemas homéricos, de finales del siglo VIII a. C., se gestaron durante siglos y se compusieron, por lo tanto, en ausencia de escritura. Como sostienen Parry y Lord estas dos obras fueron composiciones de oralidad primaria, ya que su existencia textual y su forma representaban una fiel reproducción de unas leyes de composición puramente acústicas (Havelock, op. cit.: 64).

Havelock también explica cómo se produjo el paso de una sociedad de la oralidad primaria a otra alfabetizada. Lo que sostiene este autor es que aunque la escritura apareció en el siglo VIII a. C., la oralidad (canto, recitación, memorización) siguió teniendo un peso fundamental en la transmisión cultural durante bastante tiempo. ${ }^{2}$ Es decir, la alfabetización no fue un cambio radical sino que se produjo de forma gradual durante los siglos que

\footnotetext{
${ }^{2}$ Sobre la fecha de invención del alfabeto hay ciertas controversias. Depende, según sostiene Havelock, de cómo se considere la cuestión de hasta dónde llegaron los logros de la oralidad primaria. La discusión sobre este asunto cae fuera del propósito de este trabajo por lo que no la abordaremos. No obstante, remito a la obra del citado autor (op. cit.) para profundizar en el tema mencionado.
} 
separan Homero de Platón y Aristóteles. Siglos que produjeron cambios y transformaciones fundamentales: desplazamiento de la importancia de una cualidad intelectual como la memoria por la capacidad lógica; ascensión a puestos de honor del sentido de la vista en detrimento del oído; desprestigio del texto poético (que se retiene fácilmente) por el texto narrativo en prosa. ${ }^{3}$

Havelock asimismo se pregunta "por qué medios (en una sociedad de la oralidad) se puede enseñar y recomendar la tradición general al conjunto de la población de modo que la comparta y viva según ella" (op. cit.: 109). Él mismo responde a esta cuestión en la obra mencionada. Nosotros también hemos querido analizarla. Apoyándonos en sus trabajos aprendimos que en la sociedad oralista primaria la enculturación se realizaba por transmisión oral y a través de la observación de las acciones humanas. El aprendizaje de la tradición es lingüístico y visual. Escuchar lo que nos dicen y observar la acción de otros en situaciones de diversión contribuye de una manera más eficaz a la interiorización de la tradición que en caso contrario. Para nosotros, es en este contexto donde se explica la importancia de los juegos; juegos que no son sólo situaciones de gozo sino de instrucción: construyen la subjetividad grupal y recrean la identidad. Así pues, los juegos desempeñaron un papel fundamental no sólo en el entretenimiento, sino en la transmisión cultural en la sociedad griega clásica, en la socialización de la población general, en la transferencia de la tradición, en el mantenimiento de la ideología dominante y del status quo, ya que contribuían a perpetuar el poder de la clase dirigente. Lo que vamos a ver, es que tanto los juegos en los poemas homéricos como los Olímpicos, Píticos, Ístmicos y Nemeos tenían esta función mencionada: son discurso oral y acción observada al servicio de la transmisión cultural y del mantenimiento del orden social. Lo importante será observar qué rasgos culturales caracterizaban la civilización de la oralidad primaria y qué debía ser interiorizado por la sociedad general. Tanto los juegos descritos en los textos homéricos como los juegos griegos mencionados reproducen un sistema de valores propios de aquellas sociedades; en los unos y en los otros hay continuas referencias a la ética de los héroes, a sus virtudes, a sus sentimientos y pasiones, al cómo comportarse y a su modo de obrar, al bien y al mal.

\footnotetext{
3 Para incrementar el conocimiento sobre estas transformaciones recomiendo una vez más el texto de Havelock (op. cit.).
} 


\section{LOS JUEGOS EN LOS POEMAS HOMÉRICOS}

Como hemos adelantado, en tiempos anteriores a Homero la sociedad era enteramente oral. Sus poesías también son orales y tienen dos propósitos: "por un lado, eran recreativas: la poesía era producto de un arte elaborado para entretener, y éste es el criterio por el cual la modernidad la ha juzgado con preferencia, habitualmente agregando la calificación de que se trataba, en algún misterioso sentido, de un entretenimiento 'elevado'. Por otro lado, hay que considerar también la poesía como funcional, como un método de conservar una 'enciclopedia' de costumbres sociales, leyes consuetudinarias y convenciones que constituían la tradición cultural griega de la época en que se compusieron los poemas" (Havelock, op. cit.: 90). De entre estas costumbres el trato que se le da a los juegos en los poemas homéricos indica que debieron tener una alta consideración en aquella época y para aquella colectividad (hay que recordar que los poemas homéricos relatan acontecimientos acaecidos durante el siglo XIII a. C.). La descripción que nos hace Homero de los mismos tiene también la doble función anunciada anteriormente: favorecer el esparcimiento y aleccionar a los ciudadanos. Un análisis de los juegos que se reproducen en Ilíada y en Odisea ${ }^{4}$ permite atestiguar su carácter educativo y ver qué modelos de comportamiento y qué valores sociales se consideraban dignos de transmitir: "la Ilíada y la Odisea nos revelan muchos aspectos de la personalidad de los griegos anteriores a la Edad de Oro, incluida su actitud frente al deporte" (Mandell, 1986: 32).

En Odisea se puede interpretar que el héroe, para poder ser considerado como tal, ha de poseer unas virtudes que se expresan con claridad en los juegos y en la retórica que los acompaña: coraje, fuerza, belleza, elocuencia, ingenio, nobleza, sensatez, salud. La descripción de los mismos no tiene otra misión que la de destacar y pregonar estas cualidades. Consideramos que este puede ser uno de los propósitos del canto VIII del poema de Homero que trata sobre la presentación de Odiseo a los feacios. Ulises se encuentra como huésped en casa de Alcinoo, rey de los feacios, al que pide ayuda para volver a su tierra. Alcinoo lo quiere presentar a su pueblo. Antes de hacerlo, Atenea, la diosa que protege a Ulises, lo hace parecer más alto y robusto para así ganarse el temor, el respeto y el corazón de los feacios, poniendo de manifiesto la importancia del cuerpo, alto y musculoso, en la valoración social.

\footnotetext{
${ }^{4}$ Para realizar este trabajo hemos consultado a Crespo, (1991), Fernández-Galiano y Pabón, (1982).
} 
Como señal de hospitalidad, Alcinoo organiza un banquete para el que sacrifica y asa doce ovejas, ocho cerdos de blancos colmillos y dos bueyes. Después de comer y beber copiosamente el aedo divino Demódoco canta hasta que Alcinoo considera que es hora de probar toda clase de juegos para ensalzar la nobleza de su gente. ${ }^{5}$ El propósito de los mismos no es otro que el de expresar la identidad y la superioridad de su pueblo (que diga Ulises que somos mejores que nadie) manifestada a través del pugilato, la lucha, saltando o corriendo. ${ }^{6}$ La narración también aborda por lo tanto el asunto del sentimiento de pertenencia grupal. Numerosos jóvenes compitieron en una carrera y ejecutaron la lucha de palmas, el salto, el lanzamiento de disco y el pugilato. En estos versos de Odisea observamos cómo se expresan las cualidades morales del pueblo faeciano. Se presentan dos actitudes y cómo este pueblo se decanta por una de ellas: "una actitud cerrada y egoísta a favor de la fuerza bruta; otra que sitúa la excelencia en un plano estético y compartido. Para los faecianos la destreza y la elegancia contaban más que la fuerza" (Mandell, op. cit:: 32 ).

Como recurso narrativo, que permite a Homero presentar las virtudes de Ulises, Laodamante, hijo de Alcinoo, lo provoca con cierto menosprecio invitándole a demostrar que su aspecto fornido vaya más allá de la estética corporal. Laodamante, dirigiéndose a Ulises le dice, "no existe una gloria mayor para el hombre que aquello que realizan sus pies y sus manos" ( $O d$. VIII 147-8). En principio, Ulises no entra en la provocación pero cuando, como consecuencia de ello, otro joven, Euríalo, se apunta a ella, viendo peligrar su estatus, cambia de opinión. Ulises replica a este feacio cuestionando que posea tres virtudes —belleza, elocuencia e ingenio — que han de darse juntas para ser consideradas como tales. Después de responder a Euríalo decide por tanto hacer alguna prueba, ya que se siente provocado (Od. VIII 184-5). Así pues empieza cogiendo un disco bien grueso y pesado que lanza más lejos que nadie. Eufórico, reta a cualquiera (excepto a Laodamante porque le proporciona hospedaje y no quiere ofenderlo) al pugilato, la lucha o a una carrera. También expresa su habilidad en el desempeño de un arco de madera y en la puntería con las flechas anticipando que debido al manejo de estos instrumentales recobrará su vida cuando esté de nuevo en su hogar. Es bien sabido que gracias a que Ulises fue capaz de tensar su arco

\footnotetext{
${ }^{5}$ Que los juegos se celebren después de comer semejante banquete no es fácilmente admisible hoy en día.

6 Esta función identitaria de los juegos permanece desde entonces. Hoy los deportes la expresan cotidianamente. No es el propósito de estas líneas entrar en ello. Tan sólo me gustaría añadir que quien esté interesado encontrará con facilidad una amplia bibliografía sobre el uso del deporte como expresión de la superioridad nacional.
} 
recuperó su honor y a su esposa ( $\mathrm{Od}$. XXI). No es irrelevante para el propósito de este trabajo poner de manifiesto que gracias a las habilidades atléticas se restituye la honra porque ello expresa la alta consideración social de los juegos en la cultura griega clásica.

Volviendo a los feacios, Alcinoo decide calmar a Ulises y da por supuesta una de las virtudes del héroe: el coraje. Asume que podría vencer a cualquier feacio en la lucha aunque termina asegurando que nadie es mejor que ellos en la danza. Ulises viendo a los danzarines reconoce su supremacía sobre cualquier otro pueblo y Alcinoo, su sensatez. Euríalo le pide perdón por la ofensa anterior y Ulises se lo dispensa deseándole salud y riquezas. Todo ello no expresa más que la nobleza del protagonista. Amén de las virtudes del héroe mencionadas, algunos estudiosos interpretan que a Ulises no le falta la capacidad de razonar. Kirk, Raven y Schofield dicen que "la concepción homérica de Odisea (...) es la de un hombre capaz de filosofar en la mayor parte de sus vías al menos, es un hombre que no se distingue tanto por la 'astucia' como por su capacidad de analizar circunstancias complejas con el resultado de elecciones racionales" (1987: 115).

$\mathrm{Si}$ en Odisea hemos visto que los juegos son expresión de identidad grupal y presentación de las virtudes del héroe, en Ilíada adquieren otras funciones. En este caso son juegos fúnebres que tiene como propósito honrar a Patroclo, amigo de Aquiles, muerto por Héctor.

En los juegos fúnebres, por su propia definición, se honra a un muerto; un muerto con un puesto importante en la estructura social. Ni qué decir tiene que hoy en día han desaparecido este tipo de juegos y sería de bastante mal gusto organizar un acontecimiento deportivo después de un entierro. No era así, sin embargo, en los tiempos de Ilíada, en donde los juegos fúnebres se celebraban a continuación de incinerar al fallecido. Consistían en pruebas atléticas y retóricas con enfrentamientos dialécticos entre los concursantes. Tal es así que "el material arqueológico demuestra la existencia de competiciones poéticas semejantes en juegos fúnebres de finales del siglo VIII y principios del VII antes de Cristo. En Atenas, por ejemplo, han aparecido cinco trípodes beocios, fechables entre 700-600 a. C., que prueban cómo estos certámenes atraían participantes de diversas localidades de Grecia. Es muy importante un fragmento aparecido en Tebas con una inscripción cuyo tipo de letra nos remonta a los primeros años del siglo VII a. C.; por ella sabemos que fue ganado en los juegos fúnebres de un tal Ecropo y que lo dedicó Isódico a Apolo" (Pérez 
Jiménez y Martínez Díez, 1997: 11). Tales juegos manifiestan la importancia de la palabra hablada en aquellos tiempos orales. Es decir, la retórica era una virtud fundamental que proporcionaba estatus a quien fuese capaz de vencer a su oponente con argumentos; de ahí que los mismos poetas participasen en los juegos en busca del reconocimiento social de su “trabajo". Por ejemplo, cuenta Hesíodo en Trabajos y Días (vv. 653-659) que hizo una travesía hacia Calcis para participar como aedo en los juegos fúnebres de Anfidamante, muerto en batalla naval. ${ }^{7}$ Como no podía ser de otra manera obtuvo la victoria con un himno y se llevó como premio un trípode de asas. El premio lo dedicó a las Musas del Helicón que le iniciaron en el melodioso canto. Según parece este hecho fue el que motivó la creación del un texto magnífico y un buen ejemplo sobre las citadas competiciones poéticas de los juegos fúnebres. ${ }^{8}$

Retomando los funerales de Patroclo, después del ritual del enterramiento — quema de su cuerpo, introducción de sus huesos en un cofre de oro y posterior colocación del mismo en una tumba - su amigo Aquiles se encarga de honrarlo por lo que "allí retuvo e hizo tomar asiento a la tropa en amplio círculo. Y sacó de las naves premios para los certámenes: calderas, trípodes, caballos, mulas, magníficas cabezas de reses, mujeres de bellos talles y grisáceo hierro" (Il. XXIII 258-61). En la carrera de carros, Aquiles otorgará al vencedor una joven hábil en hermosas labores y un trípode de asas; al segundo, una yegua de seis años no domada y preñada; al tercero, un caldero bien grande reluciente y hermoso; al cuarto, dos talentos de oro; y al quinto, un caldero con dos asas. Cinco aurigas compiten por los premios: Eumelo, Diomedes Tidida, Menelao, Antíloco y Meriones.

Néstor Nélida, padre de Antíloco, aconseja a su hijo sobre cómo obtener la victoria. Dice que en la carrera de carros es más importante la cautela, la prudencia y la habilidad que la fuerza. Da comienzo la carrera ${ }^{9}$ y todos pelean con gran coraje y pundonor porque desean el triunfo. Los dioses comienzan a intervenir apoyando a sus pupilos: Atenea a Diomedes el Tidida que, finalmente, llega el primero. Le siguen Antíloco, Menelao,

\footnotetext{
${ }^{7}$ Sobre la fecha en que murió Anfidamante y acerca de la fijación cronológica de la batalla en la que falleció hay serias dudas. Dudas que salpican la misma cronología del poeta Hesíodo (Pérez y Martínez. op. cit.: 15).

${ }^{8}$ No queremos alargarnos sobre el Certamen. Tan sólo resumiremos esta estupenda obra diciendo que consiste en un toma y daca verbal entre los dos grandes poetas de la cultura griega clásica. El autor del Certamen, que según parece pudiera ser Alcidamante, "concede la victoria a Hesíodo (...) porque depende de la noticia incluida por aquél en los Trabajos, ya que el tono general de la obra es abiertamente favorable a Homero y no a Hesíodo que se presenta siempre contrariado por el acierto de sus respuestas" (Pérez y Martínez, op. cit.: 384).

${ }^{9}$ Sobre la descripción de la carrera, (Crespo, 1991: XXIII).
} 
Meriones y Eumelo. Aquiles se apiada de Eumelo y decide darle el segundo de los cuatro premios, a lo que Antíloco se opone diciéndole a Aquiles que si Eudemo fuese valiente debería haber rogado a los dioses inmortales para no ser el último. Aquí radica un dato importante: el vencedor tenía el apoyo de los dioses por lo que honrarlo era ensalzar a los dioses. Al final Aquiles da la razón a Antíloco y le deja su yegua, aunque incrementa el premio de Eumelo. Aquí no termina el asunto. Menelao está ofendido con Antíloco al que le acusa de insensato y tramposo. La respuesta de Antíloco, el prudente, merece ser reproducida en su totalidad:

\footnotetext{
"Tranquilízate ahora. Yo soy mucho más joven que tú, soberano Menelao, y tú eres mayor y de más valía. Sabes cómo resultan los excesos de un hombre joven: rauda es la imaginación, pero poco sutil el ingenio.

Por eso, que tu corazón tenga paciencia: yo mismo la yegua que he ganado te la daré. Y si además otra cosa de mi casa aún mayor me reclamaras, bien pronto preferiría dártela antes que a ojos tuyos, criatura de Zeus, perder para siempre el afecto de tu ánimo y parecer un criminal a las deidades" (Il. XXIII 587-95)
}

En estos versos, y en los anteriores, se ponen de manifiesto gran parte de las virtudes de los héroes homéricos: paciencia, prudencia, madurez, generosidad, comprensión, tolerancia con la juventud, juicio, pensamiento pausado, amistad antes que gloria, coraje, pundonor, deseos de triunfo, protección de los dioses, etcétera. La narración termina con que Menelao recibe la yegua de Antíloco y se da cuenta de que ha hablado con cólera por lo que pide perdón. Antes de la conclusión del relato, Homero vuelve a poner de manifiesto su tarea educativa cuando aboga por el respeto a los ancianos. Aquiles honra con otro premio a Néstor porque debido a su vejez ya no podrá participar en juegos similares; juegos en los que en el pasado obtuvo grandes éxitos.

Otros esparcimientos son narrados: pugilato, lucha, carrera, combate, lanzamiento del peso, juego del arco, lanzamiento de jabalina. Todos ellos tienen sus premios y sus protagonistas pero lo que queremos destacar es que a través de la narración de los mismos se reproducen una y otra vez gran parte de los valores socioculturales mencionados en la carrera de carros. Es decir, todos estos relatos constituyen verdaderas guías de comportamiento. Su propósito no es mero entretenimiento sino educativo: que dichos valores sean memorizados e interiorizados por la sociedad micénica de entonces y entren a 
formar parte de la subjetividad colectiva. Se puede considerar, por lo tanto, que los guerreros-aristócratas practicaban la caza, realizaban carreras de velocidad y de fondo, pugilismo y otras pruebas para patentizar la posición social, con vistas a alcanzar el heroísmo de los protagonistas de los poemas épicos de Homero y como entrenamiento para la guerra; de este modo adquirían simbólicamente un estatus y una reputación de atletas invulnerables, porque su buen desempeño significaba tener el favor de los dioses. Sobre las clases populares, los datos son meras especulaciones que no permiten concluir si la mayoría de los micenos "humildes" también practicaba alguno de los "deportes" mencionados.

\section{Juegos Olímpicos, Píticos, Ístmicos, Nemeos}

En el apartado anterior nuestra intención ha sido poner de manifiesto cómo el lenguaje hablado, en una sociedad de la oralidad primaria, tenía entre sus funciones la socialización de la colectividad. Los juegos descritos en los poemas homéricos ejemplifican este propósito. La descripción del ritual lúdico, los valores atribuidos a los vencedores, el proceso de adjudicación de los premios, etcétera, constituyen la cultura mental que se desea propagar.

Ahora llega el momento de analizar cómo la observación complementa la socialización colectiva. Como sostiene Havelock, "La tradición se enseña mediante la acción y no mediante ideas o principios. Para su enseñanza las sociedades orales deben procurarse un contexto adecuado para la actuación, a la que asisten oyentes invitados o que se hayan invitado ellos mismos a fin de participar en lo que es, por un lado, un lenguaje de especialistas pero, por otro, un lenguaje en el cual participan en mayor o menor grado todos. La inclinación natural de los seres humanos a divertirse (...) suscita fiestas comunes y sentimientos comunes, sentimientos compartidos por todas las sociedades orales y centrales para su funcionamiento exitoso, en cuanto proporcionan las necesarias situaciones de instrucción" (op. cit.: 111). Otros autores han expresado la misma idea: "Para dar al conjunto de la sociedad una forma concreta y visible del orden cósmico o de la teología imperantes, hay que recurrir a frecuentes actos públicos y festivales simbólicos en los que participantes y espectadores (...) experimentan una profunda sensación de solidaridad colectiva y de orgullo personal así como el omnipresente poder de las divinidades" (Mandell, op. cit.: 13-14). 
En nuestra opinión, ésta es la razón de los juegos griegos: Olímpicos, Píticos, Ístmicos, Nemeos ${ }^{10}$ cuyos antecedentes se hallan en los juegos fúnebres mencionados en los poemas homéricos. De hecho, los datos que proceden de las excavaciones arqueológicas permiten aseverar que el emplazamiento de Olimpia fue usado como lugar de culto (donde probablemente se realizaron juegos en honor de los difuntos) durante el milenio anterior al primer acontecimiento "deportivo" y a la primera coronación de un vencedor en 776 a. C. ${ }^{11}$ Según se desprende de estos estudios, los juegos fúnebres ampliaron su significado y su función, celebrándose en ocasiones no luctuosas, pero no sabemos cómo se produjo esta transición. En cualquier caso, los juegos resultantes —Olímpicos, Píticos, Ístmicos, Nemeos- se iniciaron durante la oralidad y vivieron la transición a una sociedad alfabetizada. Ya hemos visto en la introducción que el tránsito de uno a otro tipo de sociedad no fue radical sino progresivo. Tal es así que "si las listas olímpicas disponibles en el siglo IV a. C., se remontaban realmente al primer cuarto del siglo VIII, su fuente no era la notación alfabética sino la transmisión oral" (Havelock, op. cit.: 118-119). Es decir, que desde Homero (s. VIII a. C.) hasta Aristóteles (siglo IV a. C.) podemos hablar de una sociedad que combina oralidad y escritura pero donde, al final del siglo IV a. C., aún el papel de la transmisión oral no es menospreciable. Los datos que presentamos en este apartado tienen sentido hasta este último siglo en el que vemos que todavía la oralidad es relevante. Ir más allá cae fuera del propósito de nuestra argumentación que no es otra que señalar el papel enculturador de los juegos en la sociedad oral griega y poner al descubierto qué tipo de valores y qué orden social se transmitía. Obviamente la sociedad que describe Homero es bien distinta de la que participa de los juegos griegos posteriores, entre otras cosas, porque entre medio nace la filosofía con lo que ello supone de cambio en la búsqueda de explicaciones distintas (racionales) a las que se dan en la tradición poética

\footnotetext{
${ }^{10}$ Habrá observado el lector que hasta ahora no ha aparecido por ningún lado la palabra deporte. Esto es así porque sport es un término que surge en la segunda mitad del siglo XIX, en Inglaterra, para definir un conjunto de pasatiempos que allí se daban: carreras de caballos, lucha libre, boxeo, tenis, caza de zorros, remo y atletismo. (Elias y Dunning, 1992).

El proceso por el que la palabra sport fue aceptada por otros países del entorno europeo viene bien descrito en la obra citada por lo que recomiendo su consulta para quien quiera profundizar en esta cuestión. En lo único que quiero insistir es en que la palabra deporte tiene un origen reciente y desde luego los griegos no la usaron para describir sus actividades lúdico-educativas.

${ }^{11}$ Esta fecha "mítica" se considera el inicio de las Olimpiadas. Sin embargo, tan sólo indica que es desde entonces desde que se conservan las listas de los vencedores en los juegos olímpicos. Según sostienen algunos investigadores, el 776 a. C., corresponde con la vigesimoctava olimpiada.
} 
(míticas). ${ }^{12}$ Sea como sea, y siendo prudentes porque no hay que olvidar todas estas transformaciones sociales, creemos que los juegos contados por Homero, Hesíodo y otros rapsodas, y los Olímpicos, Píticos, etcétera, compartían un mismo fin ya expuesto con anterioridad: transmitir la cultura.

Así pues, los juegos Olímpicos se celebraban cada cuatro años en Olimpia; los Píticos (en Delfos) y los Nemeos (en Nemea) se convocaban también con el mismo intervalo de tiempo pero alternados; y los Ítsmicos (en Corinto) cada dos años. Como resultado, cada año prácticamente se celebraban unos u otros por lo que su función en el mantenimiento de la paz era relevante. Es bien sabido que todos los juegos se acompañaban de treguas que aseguraban la concordia antes y durante el desarrollo de los mismos. Además de los participantes, de los que ahora hablaremos, llegaban innumerables ciudadanos griegos siendo su asistencia como espectadores uno de los puntos culminantes de sus vidas ${ }^{13}$ : hombres de negocios, malabaristas, magos, videntes, vendedores ambulantes y también filósofos. Según parece, Tales de Mileto murió de calor y de sed a los 78 años durante los juegos de 548 a. C., en los que el ambiente de feria, polvo y griterío debía ser insoportable (Mandell, op. cit.)

No se permitía participar a los "bárbaros" es decir a aquellos que no pertenecían a la comunidad griega. De este dato podemos inferir que los juegos permitían recrear la identidad nacional de los griegos, probablemente desunidos. Es obvio que diferentes culturas griegas convivían dentro del territorio griego y los juegos servirían para expresar sus diferencias y la superioridad "étnica". Las diferentes concepciones del mundo se observan de manera clara entre los ilustres jonios atenienses y los dorios espartanos. Los primeros, se sentían más atraídos por el individualismo, y menos por la lucha, el belicismo y la disciplina del cuerpo. Los dorios espartanos, con una férrea disciplina de grupo, sí que disciplinaban su cuerpo con ejercicios gimnásticos diversos y escasez de comidas. Estaban obsesionados por la preparación militar y por la física. Fruto de esta mentalidad colectiva "nacen" los atletas de Esparta que son un modelo para el mundo griego porque acaparan gran parte de las victorias: “entre los XV Juegos Olímpicos (720 a. C.) y los L (576 a. C.)

\footnotetext{
${ }^{12}$ En este trabajo no abordo ni los factores que favorecieron el nacimiento de la filosofía, ni los cambios y las transformaciones que se produjeron en la sociedad griega como consecuencia de este alumbramiento. Tan sólo quiero dejar constancia de este acontecimiento, anunciado en la poesía de Homero y Hesíodo, por lo que supuso en la búsqueda de explicaciones racionales, y no míticas, sobre el ser, la verdad y el bien.

${ }^{13}$ Las mujeres tenían prohibida la presencia en los estadios y, en consecuencia, la participación.
} 
los atletas espartanos fueron proclamados campeones 56 veces sobre un total de 71 victorias" (Mandell, op. cit.: 43).

Una característica común a todos los participantes en los juegos consistía en ser griegos de la nobleza (hombres y no mujeres) lo que ponía de manifiesto el carácter masculinizado y de ostentación de estos festivales. Los juegos también tenían un importante carácter religioso (los Ístmicos quizás menos, según dicen algunos estudiosos). Se creía que habían sido instituidos por un dios u otro y se celebraban en honor a ellos. Tal vez por ello fueron suspendidos, con la hegemonía del cristianismo (393 d. C.), por el edicto de Teodosio el Grande que prohibió las fiestas paganas (VVAA, 2004: 296).

Participar en los juegos era sinónimo de distinción social. De hecho los juegos olímpicos (seguramente al igual que los otros) eran una afirmación más de la cultura griega que respondía a los ideales y objetivos de una aristocracia que extendía sus diversiones y concursos a todas las demás clases sociales (VVAA, op. cit.: 308).

Los juegos olímpicos duraban cinco días. El primero se dedicaba a los juramentos y la ofrenda de sacrificios rituales. En el segundo comenzaban las competiciones propiamente deportivas en el hipódromo: carrera de cuádrigas y de caballos. Este mismo día se celebraba el pentatlón: lanzamiento de disco, salto de longitud, lanzamiento de jabalina, prueba de velocidad y lucha. Durante la noche continuaban los sacrificios, algunos en honor de Pelops. Dice la leyenda que los juegos que se celebraron para honrarlo por su muerte fueron los primeros juegos olímpicos. ${ }^{14} \mathrm{El}$ tercer día daba paso a las carreras pedestres: fondo, prueba de velocidad y la de 400 metros. La cuarta jornada se dedicaba a la lucha, el boxeo, el pancration y la carrera de los soldados de infantería. Y el último día se consagraba a las procesiones, ceremonias rituales y banquetes. ${ }^{15}$

Los premios por las victorias eran simbólicos lo que justificaba la interpretación del carácter "amateur" de los juegos: coronas de olivo silvestre en Olimpia; en Delfos, de laurel; en Corinto de pino y en Nemea de hojas de apio. Sin embargo, los campeones adquirían gran celebridad y cuando volvían a sus ciudades, recibían un sinfín de honores ${ }^{16}$

\footnotetext{
${ }^{14}$ Anteriormente ya dijimos que el nacimiento de los juegos griegos podría tener su origen en los juegos fúnebres narrados por Homero y Hesíodo.

${ }^{15}$ Una descripción más detallada de todas y cada una de estas pruebas puede consultarse en Mandell, (op. cit.).

16 Actualmente sucede algo parecido aunque el análisis del contexto sociocultural donde se produce la "construcción" del héroe no es objeto de consideración en este estudio.
} 
—les levantaban estatuas o retratos_ y recompensas sustanciosas: dinero, aceite de oliva, trípodes, vasos de bronce, etcétera. Las ciudades recompensaban a sus vencedores con privilegios porque la victoria también recaía sobre ellas incrementando su estatus dentro del mundo griego. ${ }^{17}$ Además, podemos inferir, que la creencia en que algún dios había "ayudado" al campeón incrementaba entre los conciudadanos el sentimiento de protección.

Los vencedores encarnaban el ideal humano de la aristocracia. El hombre ideal quedaba definido por tres características: la areté, valor y cualidades físicas y morales que son transmitidas por tradición y heredadas de antepasados ilustres; la calocagazia, bondad y belleza; y la sofrosine, moderación, autodominio, actitud serena.

También los escultores están al servicio de este orden social. Las estatuas son seres ideales, desnudos la mayor parte de las veces, y no retratos personales que representan vencedores con las virtudes del noble (belleza, serenidad). En palabras de Mandell: "Se atribuye a los atletas espartanos la iniciativa de abandonar los calzoncillos tradicionalmente empleados en la práctica y la competición deportiva, a favor de la unción del cuerpo, libre de cualquier vestimenta, con aceite de oliva (...) Los jóvenes y apuestos griegos aprovechaban cualquier oportunidad para exhibir sus cuerpos bronceados y para criticar o alabar las imperfecciones o la belleza corporal de los demás. De hecho, la belleza física constituía uno de los medios más prestigiosos de ganarse el respeto de sus conciudadanos" (op. cit.: 42).

El arte griego ha reproducido abundantes escenas "deportivas" poniendo de manifiesto que los pasatiempos lúdicos eran motivo de inspiración: esculturas en mármol de corredores griegos, de luchadores desnudos, de atletas preparándose para la competición, etcétera, y vasos y ánforas con pugilistas, corredores a pie, entrenadores aconsejando a sus pupilos. Asimismo la literatura — poesía y prosa — ha glorificado a los vencedores. Píndaro (522 a. C.) es uno de los máximos exponentes de esta tendencia. Su obra refleja que la poesía, una vez más, estaba al servicio del mantenimiento del orden social de la nobleza en un período en que dominaba el aparato estatal.

\footnotetext{
17 Hoy en día también se reproduce esta transferencia simbólica. Es decir, que la ciudad se apropia simbólicamente de las virtudes y glorias de sus mejores deportistas. Esto explicaría, en cierta medida, los recibimientos masivos de los ciudadanos a los equipos deportivos que los representan cuando obtienen una victoria relevante en una competición.
} 
Progresivamente se profesionaliza la participación en los juegos. La competición era elevada, y para vencer había que tener una buena preparación que consistía en hacer gimnasia, llevar una correcta alimentación, descansar lo suficiente y someterse a masajes. Nacen los entrenadores, mecenas y patrocinadores que desean alcanzar éxitos en su propio beneficio. Curiosamente, el inicio de la profesionalización coincide con la pérdida de relevancia del oralismo: "A partir del siglo $\mathrm{V}$ a. C., noble-deportista-amateur (héroe homérico por excelencia) desaparece completamente de la competición pública" (Mandell, op. cit:: 76). Curiosamente coincide también con la hegemonía ateniense (con el menor interés que, como hemos visto, sentían hacia los juegos) y con la entrada en crisis de la nobleza durante el siglo $\mathrm{V}$ y el aumento en los órganos de poder de la burguesía. Esto es relevante porque indica un cambio de mentalidad social en la Grecia de entonces, un cambio en la concepción del mundo que se patentiza en los juegos (del noble deportista amateur se da paso al profesionalismo) y seguramente en otras manifestaciones culturales griegas. A partir de ahí, los juegos olímpicos, y otros, continuarán con sus funciones lúdicoeducativas, quizás con una menor relevancia, pero expresarán otras características definitorias de la "nueva" sociedad griega alfabetizada, ateniense, burguesa y filósofa que frecuentaba las instalaciones deportivas para transmitir sus enseñanzas. Se sabe que Atenas contó con tres gimnasios ${ }^{18}$ - la Academia, el Liceo y el Cynosarges- y que Platón y sus pupilos frecuentaban el primero de ellos que adquirió con el transcurrir del tiempo el significado que hoy tiene de institución pedagógica.

\section{CONCLUSIÓN}

La Grecia que cantan los poemas homéricos (s. XIII a. C.) y la que transcurre hasta Aristóteles (en el sigo IV a. C.) era oral aunque en los últimos tiempos (sobre todo a partir de Homero en el s. VIII a. C.) convivieron cultura oral y escrita, en un proceso de transformación progresivo.

Esto quiere decir, entre otras cosas, que la socialización se producía por medio de la palabra. La poesía, amén de servir para el entretenimiento, tenía gran importancia en la transmisión cultural. Pero también, junto con la escucha de rapsodas, aedos, sacerdotes,

\footnotetext{
${ }^{18}$ Los gimnasios de entonces no eran obviamente como los de ahora. La diferencia esencial reside en que eran puntos de encuentro para la ciudadanía masculina donde se jugaba y donde circulaba la palabra (noticias, tertulias, chismorreos, etcétera).
} 
cantores, etcétera, la colectividad interiorizaba su cultura observando las acciones de los demás.

En este punto es donde adquieren importancia los juegos. Analizando los narrados por Homero y Hesíodo y los escritos de otros estudiosos sobre los Olímpicos, Píticos, Ístmicos y Nemeos hemos concluido que los juegos griegos tenían una interesante función en la enculturación social. A través de la escucha de los versos y de la participación como espectador, la población interioriza una concepción del mundo, cuyo hombre ideal (hasta el siglo V a. C.) era el héroe homérico y olímpico: el noble deportista amateur al que se atribuyen virtudes — areté - como valor, coraje, pundonor, deseos de triunfo, nobleza; bondad, amistad y belleza (calocagazia); moderación, autodominio, serenidad, paciencia, pensamiento pausado, prudencia, sensatez (sofrosine). Los juegos tenían también un importante papel en la formación de un sentimiento de pertenencia colectiva y de orgullo de la identidad en una nación como la griega, sujeta a múltiples inestabilidades.

A partir del siglo V a. C. desaparece de los juegos el noble-deportista-amateur y surge poco a poco el profesionalismo como consecuencia de los cambios sociales acontecidos. Si como sabemos los juegos continuaron celebrándose, es fácil plantear la hipótesis que las transformaciones sociales les afectaron. Esto no quiere decir que perdieran su función educativa (que todavía hoy mantienen) sino tan sólo que alteraron su mensaje para adaptarlo a su momento, un momento económico, político y social distinto.

\section{BIBLIOGRAFÍA}

Crespo, G. E., 1991, Homero. Iliada. Gredos, Madrid.

Fernández-Galiano, M. y M. J. PABón, 1982, Homero. Odisea. Gredos, Madrid.

Elias, N., Y E. DunNing, 1992, Deporte y ocio en el proceso de la civilización. Fondo de Cultura Económica, México.

HAVELOCK, E.A., 1996, La musa aprende a escribir. Reflexiones sobre oralidad y escritura desde la antigüedad hasta el presente. Paidos, Barcelona. 
KiRK, G. S., J. E. RAVEN y M. Schofield, 1987, Los filósofos presocráticos. Gredos, Madrid.

MANDELL, R. D., 1986, Historia cultural del deporte. Bellaterra, Barcelona.

PéReZ, J. A., Y D. A. MARTíneZ, 1997, Hesíodo. Obras y fragmentos. Gredos, Madrid.

VVAA, 2004, Historia Universal. Grecia (I), EL País/Salvat, Vol. 4, Madrid. 